\title{
Knowledge Management and E-Learning Effectiveness: Empirical Evidence from Jordanian Higher Education Institutions
}

\author{
https://doi.org/10.3991/ijet.v15i05.11653 \\ Mohamad Noor Al-Jedaiah \\ Jadara University, Irbid, Jordan \\ mjedaiahejadara.edu.jo
}

\begin{abstract}
The objective of this research is to investigate the effect of KM on EL effectiveness in private universities. Random sample of academic staff in private universities were selected. The sample individuals occupy different academic levels in these universities. The collected data was analyzed using descriptive and inferential statistics to accomplish objectives and reach results. The results showed that private universities do not have clear KM strategies and plans, which affect negatively the effectiveness of EL in these universities.
\end{abstract}

Keywords-E-learning effectiveness, knowledge management, higher education

\section{Introduction}

The necessity of knowledge management (KM) received higher attention in the last years. Knowledge management of organizations will determine the processes that the knowledge will be retained, exchanged and enriched over years [1]. It has been defined as the process that enables the organization to create, store, transform and exchange knowledge within the organization [3].

Universities face challenges in creating and exchanging knowledge. These challenges resulted of the lack of KM strategies the organize KM in all directions [1]. Universities should adopt the knowledge-based theory to improve competiveness and improve performance. The theory based on discovering knowledge, its acquisition, creation and disseminate and transmit this knowledge through teaching [2].

The other side that should be introduced is the interaction of humans with Elearning (EL) and how it is interacting with KM. E-learning interferes with all the stages of KM in organization [19]. This interaction included the acquisition, storing, exchange and dissemination of knowledge. The success of E-learning depends in the inputs used to apply this system and the way people react with this system [5]. All definitions of E-learning concerned with the process E-learning took place [22].

The lack of integration between KM and E-learning in universities will minimize the efficiency of E-learning, as well as moving it away of its objectives. The objectives of EL should be determined previously through the determination of the 
type of knowledge required to be transferred to students and exchanged among students. These objectives can be determined through the teachers at these universities and the administration of the university.

The lack of guide for EL systems at the university and the objectives of these EL systems may cause its less productivity and create moody usage of these systems among students. The introduction of clear roots of EL and its tight link with knowledge sharing and management will improve the value of EL among students and encourage them to concentrate on as alternative of the traditional classroom knowledge transfer. So, this paper will investigate the effect of KM practices on EL through the concentration on the KM practices and its connection to EL efficiency in higher education institutions.

\section{Literature Review}

\subsection{Knowledge management concept}

Knowledge management (KM) became vital in higher educational organizations [19]. It plays an important role in the inputs and outputs of the educational process. The improvement of students' knowledge is connected directly to the knowledge these higher educational institutions have. Knowledge management is related to both organization learning and innovation management [10].

To know how to manage knowledge, it deserves to know the definition of knowledge. Knowledge has been defined as the believes, truths, concepts and perspectives, judgements, and know-how [17]. The definition reflects the collection of all required information concerning some issue either this information stored somewhere or gained from external sources to be able to solve this issue as required. This definition indicates the extent knowledge is very important to organization concerning competitive advantage [4]. The organization needs to meet the users' needs in one direction and to have the ability to management its knowledge and resources related to accomplish that [18].

This requires from higher educational institutions to recognize what kind of knowledge they have? How this knowledge can be classified and sorted? How to store and disseminate this knowledge among its learners as well as building the proper tools to do? This leads the higher educational institutions to build their own knowledge model to concentrate. This leads to the definition of management, which is the arrangement of processes needed to collect knowledge and the tools that should be used manage this knowledge.

\subsection{Processes of knowledge management}

The previous definition of knowledge management pointed out that their should be processes and systems used to achieve this management [4]. The following parts explain the processes the knowledge pass to be established and lived by all member of the institution. 
Create knowledge: The creation of knowledge can be classified two types of knowledge. The first type of knowledge that is build inside the organization due to experience gained through the staff and the external knowledge, which can be brought to one institution. These two types of knowledge created should meet the students' needs $[17,21]$.

Capture knowledge: The created knowledge in further stage requires capturing. Capturing means collect the knowledge created arrange it and sort it to be used for further stage in institution.

Refine knowledge: The captures knowledge should be placed in the context of institution to be practiced to become part of the institution knowledge [4].

Store knowledge. The knowledge of the organization should be stored using available tools to avoid its loss and enrichment in the future.

Management knowledge: The knowledge the institution have should be managed in away that it reaches al members of the institution to be benefits in the context of work.

Disseminate knowledge: It is the method used to make knowledge moves within the institution to assure equal benefits of this knowledge [10]. The following chart shows the cycle KM elements strategy (Figure 1).

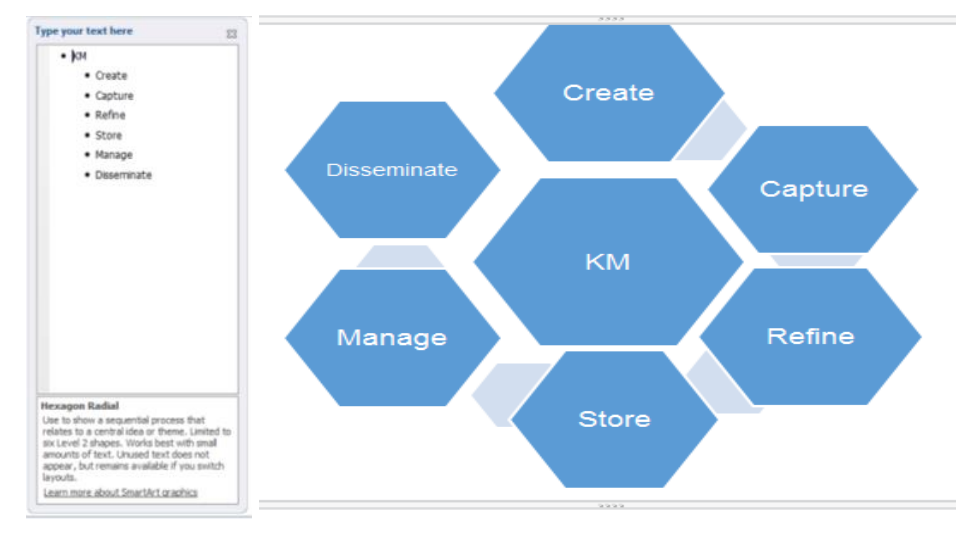

Fig. 1. KM cycle [17]

Human is the share point between KM management and practice as well as the user of E-learning tools. To explain this interaction, it deserves to explain human interaction with knowledge. A model introduced that shows this interaction [12]. The model in its base explain the self-service of human to gain knowledge and passing different stages to reach the stage that concerns with the transfer of best practices (Figure 2). 


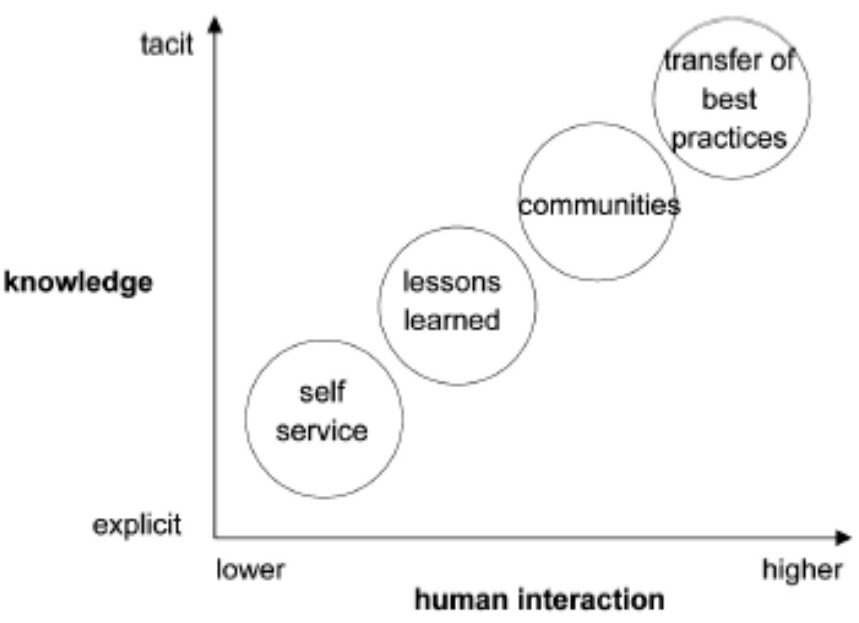

Fig. 2. The interaction of humans in different stages of knowledge [12]

\subsection{E-Learning concepts and tools}

Electronic learning utilizes electronic available tools to make it more easy for learners to gains and share information [13, 15]. With the rapid development in technology, the number of available tools that can be used in EL increased widely [6]. Electronic learning can be seen as an advancement that can provide the learner with more variety of information overtime more than the traditional classrooms [15].

Wide variety of electronic tools has been investigated to be used in EL. Smart mobiles and tablets were popular electronic tools that has been investigated in EL systems $[11,14]$. The use of these tools were discussed according to possibility of the use of these sets by learners as EL tools. On the other hand, the usage of these tools, according to research, are connected with the strategy adopted by the institution to utilize these tools efficiently to transfer knowledge among users. This indicates that the EL tools should be planned to serve the KM plans and strategies the institution.

\subsection{Knowledge management and E-learning}

Wide range of roots that can be used in EL, which includes web-based learning and training, online learning, online training, web-based interaction. The use of different roots depend on the objective and the KM parts needed to be spread among learners. In this regard, the educational institution should design specific tool for each knowledge component to be able to transfer knowledge among learners [4].

Electronic efficiency has been investigated using learning management system (LMS) [15]. The study found that LMS can be improve online learning through the focus on the scientific material and the use of electronic tools to practice different activities that measure the students achievement of courses including quizzes, tests and running surveys as well as executing projects as part of the courses. 


\section{$3 \quad$ Methodology}

Problem statement: E-learning became one of the regular practices in higher education as available cheap tool to communicate students in higher education. The usage of e-learning in universities should be accompanied with action strategy to maximize the benefits of this tool and to provide guidance for students how to benefit from this new technology to save their time and to maximize their abilities to gain knowledge in short and long run. As e-learning became a major tool to communicate universities, the culture of the university should encourage its students to rely on this tool to exchange communication and knowledge. The effectiveness of knowledge management using E-learning requires researching in Jordan to measure the extent it accomplish the objectives and figure out some solution to maximize the benefits of its use in these universities.

Research objectives: The objective of this research is to investigate the effectiveness of using E-learning in knowledge management in graduate and higher education in private universities in Jordan.

Research questions: To accomplish the objectives of this research, the following questions will be answered: what is the effect of knowledge management (acquisition, generation, implementation, and storing) on the effectiveness of using E-learning in private universities in Jordan?

Research hypothesis: To answer the questions of this research, the following hypothesis will be tested: There is not significant effect of knowledge management (acquisition, generation, implementation, and storing) on E-learning process in private universities in Jordan.

Significance of the study: This study will figure out the effect of knowledge management in universities on the effectiveness of E-learning. The results of the study will help the teaching organizations to care for knowledge management to improve the usage of E-Learning as a new tool toward students.

Study population and sampling: The population of the study included all the private universities in Jordan. The sampling unit will be teaching staff of these universities to measure their point of view concerning the extent of knowledge management practices and its impact on E-learning effectiveness. Due to the difficulty of accessing all private universities, this research will use the private universities in Northern area of Jordan including: Jadara University, Irbid al-Ahlia, Jarash alAhli, and Ajloun Alwataneah. The population of the academic staff in these universities include 350 teachers. Simple random sample was selected of the teaching staff in these universities using simple random calculator. Total number of questionnaire distributed was (183). The recovered number of questionnaire was (101) with a response rate reach $55.2 \%$.

Variables and measurements: The study composed of knowledge management $(\mathrm{KM})$ as independent variable. Knowledge management was measured through the following sub-variables include the knowledge acquisition (KA), storing (KS), generation $(\mathrm{KG})$ and implementation $(\mathrm{KI})$. While the dependent variable was the effectiveness of E-learning (EL) through the sub-variables (ability to achieve goals $(\mathrm{AAG})$, Excellence $(\mathrm{E})$, and quality of education $(\mathrm{QE}))$ in these universities. The 
study used descriptive statistics to describe each of the independent and dependent variable (mean and standard deviations) and the inferential statistics was used to measure the effect of each component of knowledge management on the effectiveness of E-learning. Normal distribution test was executed to figure out the possibility to use parametric measures. Moreover, the reliability analysis was executed to measure the possibility of generating the results of this research. The following diagram shows the distribution and effect of independent variables and dependent variable of the study.

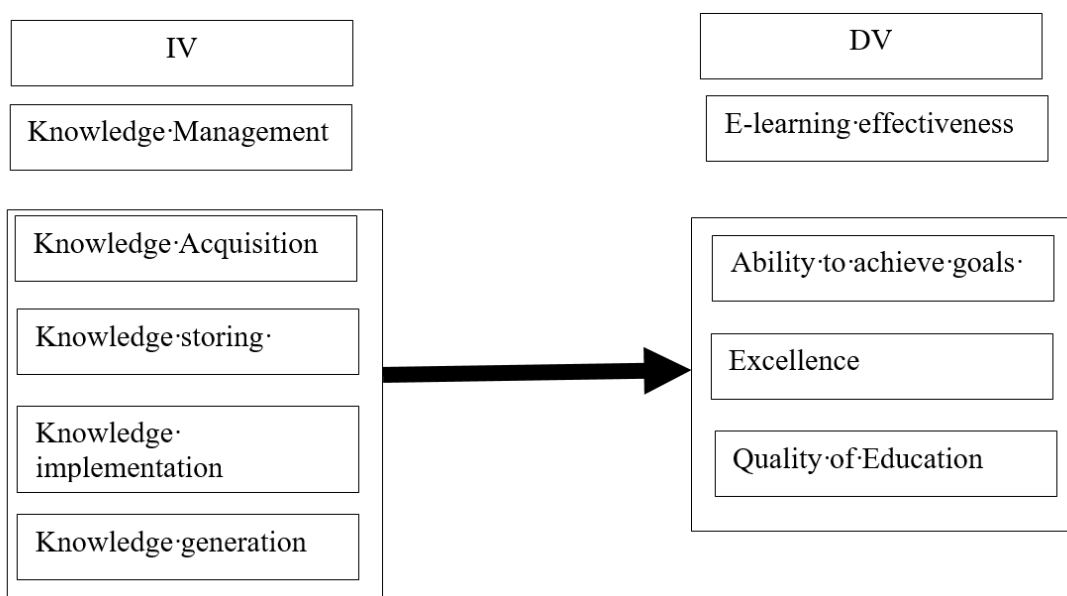

Fig. 3. Research model

Data collection tools: Questionnaire was designed for data collection. The questionnaire included three parts. The part was designed to collect the demographic data of teachers at private universities. The demographic characteristics included: gender, educational level, experience at the current university, functional experience, and academic rank. The second part of the questionnaire was designed to collect information about the IV. Likert's five scale was used to evaluate the items of the different variables. The IV part included four sub-parts representing the variables knowledge acquisition, storing, implementation and generation. Each variable included five items concerned to measure the same variable. The third part of the questionnaire included items that measure E-learning effectiveness. The evaluation of these items used Likert five scale.

\subsection{Validity and reliability}

Validity: To measure the validity of the questionnaire, the questionnaire was distributed on 15 teachers outside the sample. The notes and feedback about the questionnaire was collected. The language and research notes were collected on the questionnaire before its final distribution. 
Reliability: To measure the reliability of this questionnaire, Cronbach's Alpha was used. The results of Table 1 show that the value of Cronbach's alpha was more than 0.6 for all variables of the study, which makes reliable.

Table 1. Reliability results using Cronbach's alpha

\begin{tabular}{|l|c|}
\hline \multicolumn{1}{|c|}{ Variable } & Value \\
\hline Implementation & 0.81 \\
\hline Storing & 0.92 \\
\hline Generation & 0.86 \\
\hline Acquisition & 0.80 \\
\hline Knowledge management & 0.95 \\
\hline Ability to achieve goals & 0.89 \\
\hline Excellence & 0.91 \\
\hline E-learning effectiveness & 0.95 \\
\hline
\end{tabular}

\section{$4 \quad$ Results}

\subsection{Normal distribution}

To determine the method of inferential statistics that will be used, normal distribution test was used. Table 2 shows the results of the normal test analysis. The results showed that all the values of skewness and kurtosis ranged from -1 to 1 indicating that all the variables are normally distributed which means that the parametric analysis will be used in inferential statistics.

Table 2. Normal distribution testing of the study variables

\begin{tabular}{|l|c|c|}
\hline \multicolumn{1}{|c|}{ Variable } & Skewness & Kurtosis \\
\hline Knowledge implementation & 0.31 & 0.63 \\
\hline Knowledge generation & 0.61 & 0.81 \\
\hline Knowledge storing & 0.53 & 0.62 \\
\hline Knowledge Acquisition & 0.41 & 0.23 \\
\hline E-learning Efficiency & 0.12 & 0.35 \\
\hline
\end{tabular}

\subsection{Demographic characteristics}

The majority of sample are males with percentage $83.2 \%$. The educational level of the sample is $\mathrm{PhD}$ with percentage $91.1 \%$, while small percentage had master degree with percentage $8.9 \%$ only. This indicates that the point of view in the effect of knowledge management on E-learning will be generated of $\mathrm{PhD}$ teachers at private universities. This point of view will reflect the experience of these teachers as a majority in private universities.

Concerning the experience of the sample, the results showed that majority of the sample have experience more than 5 years. This indicates that this experience will be the evaluation of the effect of knowledge management on E-learning effectiveness 
through deep practical experience in the field of teaching. Moreover, the functional experience showed that most of the sample have more than 5 years as functional experience indicating good experience to evaluate the effect of knowledge management on E-learning effectiveness. Also, the distribution of percentage of different academic ranks will help to collect point of views of different level in the subject of this research.

Table 3. Descriptive characteristics of the sample

\begin{tabular}{|l|l|c|c|}
\hline \multicolumn{2}{|c|}{ Character } & Frequency & percentage \\
\hline \multirow{4}{*}{ Gender } & Male & 84 & 83.2 \\
\cline { 2 - 4 } & Female & 17 & 16.8 \\
\cline { 2 - 4 } & Total & 101 & 100.0 \\
\hline \multirow{5}{*}{ Education level } & M.A. & 9 & 8.9 \\
\cline { 2 - 4 } & Ph.D. & 92 & 91.1 \\
\cline { 2 - 4 } & Total & 101 & 100.0 \\
\hline \multirow{5}{*}{ Functional experience } & Less than 5 Years & 40 & 39.6 \\
\cline { 2 - 4 } & From 5 to less than 10 Years & 49 & 48.5 \\
\cline { 2 - 4 } & From 10 to less than 15 Years & 9 & 8.9 \\
\cline { 2 - 4 } & Over 15 Years & 3 & 3.0 \\
\cline { 2 - 4 } & Total & 101 & 100.0 \\
\hline \multirow{5}{*}{ Academic Rank } & Less than 5 Years & 21 & 20.8 \\
\cline { 2 - 4 } & From 5 to less than 10 Years & 35 & 34.7 \\
\cline { 2 - 4 } & From 10 to less than 15 Years & 29 & 28.7 \\
\cline { 2 - 4 } & Over 15 Years & 16 & 15.8 \\
\cline { 2 - 4 } & Total & 101 & 100.0 \\
\hline & Professor & 2 & 2.0 \\
\cline { 2 - 4 } & Associate professor & 34 & 33.7 \\
\cline { 2 - 4 } & Assistant Professor & 101 & 100.0 \\
\cline { 2 - 4 } & Teacher & 50.5 \\
\cline { 2 - 4 } & Total & 14.9 \\
\hline
\end{tabular}

\subsection{The attitudes of knowledge management}

The results showed that the practice of KM in private universities is not enough as the evaluation of attitudes was intermediate. The cause of this intermediate evaluation of KM practices is the lack of clear KM strategies in these universities. This appears through the low evaluation of knowledge generation with mean (3.14), knowledge acquisition with mean (3.42). The evaluation of knowledge storing and implementation was higher that their mean exceeded (3.5). The variation of evaluation of the different components indicate the lack of KM models in private universities. 
Table 4. The attitudes of teachers for knowledge management in private universities

\begin{tabular}{|l|c|c|}
\hline \multicolumn{1}{|c|}{ Variable } & Mean & Standard deviation \\
\hline Knowledge storing & 3.74 & 0.69 \\
\hline Knowledge implementation & 3.61 & 0.65 \\
\hline Knowledge acquisition & 3.42 & 0.69 \\
\hline Knowledge generation & 3.14 & 0.93 \\
\hline Knowledge management & 3.38 & 0.63 \\
\hline
\end{tabular}

\subsection{Attitudes of E-learning effectiveness}

The evaluation of EL effectiveness was more positive compared to KM with mean (4.06). This means that universities care for the availability of EL tools toward the objectives of teaching goals. This appears through the higher evaluation of the ability to achieve goals through EL process with mean (4.27). Also, the excellence evaluation was high with mean (4.08). The least evaluation was for the quality of education with mean (3.99). This approves the previous discussion that EL is not connected with other strategies to improve the quality of education in private universities.

Table 5. The attitudes of teachers for E-learning effectiveness in private universities

\begin{tabular}{|l|c|c|}
\hline \multicolumn{1}{|c|}{ Variable } & Mean & Standard Deviation \\
\hline Ability to achieve goals & 4.27 & 0.49 \\
\hline Excellence & 4.08 & 0.4 \\
\hline quality of education & 3.99 & 0.45 \\
\hline E-learning effectiveness & 4.06 & 0.41 \\
\hline
\end{tabular}

\subsection{The effect of knowledge management on E-learning effectiveness}

Effect of KM on EL effectiveness: The results showed that the effect of KM components was limited. The results showed that showed that KM components explain only $37 \%$ of the EL effectiveness. This indicates that the EL efficiency is connected highly with the existence of integrated KM strategy with the educational organization. The results showed that the highest effect was for knowledge storing and knowledge implementation, which had the higher management in the educational organizations. Moreover, the results showed that the knowledge generation and storing did not have significant effect on EL efficiency because these two components have lower management in private universities included in this study.

Table 6. The multivariate analysis of KM components on EL effectiveness

\begin{tabular}{|c|c|c|c|c|c|c|c|}
\hline The dimension & B & $\mathbf{T}$ & Sig & $\mathbf{R}$ & $\mathbf{R}^{2}$ & $\mathbf{F}$ & Sig. \\
\hline knowledge acquisition & 0.08 & 0.58 & 0.56 & \multirow{4}{*}{0.61} & \multirow{4}{*}{0.37} & \multirow{4}{*}{14.18} & \multirow{4}{*}{0.00} \\
\hline Generating knowledge & 0.16 & 1.37 & 0.18 & & & & \\
\hline Knowledge storing & 0.35 & 3.35 & 0.00 & & & & \\
\hline Knowledge implementation & 0.40 & 4.18 & 0.00 & & & & \\
\hline
\end{tabular}

The effect of KM components on the ability to achieve objectives: The effect of $\mathrm{KM}$ components on the ability to achieve objectives was low as it explains only $26 \%$ 
of these objectives. This result indicates that the design of $\mathrm{KM}$ in these universities that connect KM to its goals is not existed. This reflects random usage of EL system without specific targets. The highest effect on the ability to achieve objectives was through knowledge generation, storing, and implementation despite the fact that this effect is not obviously translated on these organizations objectives due to the lack of organized KM processes.

Table 7. Multivariate regression analysis for the KM components on the ability to achieve objectives

\begin{tabular}{|c|c|c|c|c|c|c|c|}
\hline The dimension & B & $\mathbf{T}$ & $\begin{array}{c}\text { Statistical } \\
\text { significance }\end{array}$ & $\mathbf{R}$ & $\mathbf{R}^{2}$ & $\mathbf{F}$ & $\begin{array}{c}\text { Statistical } \\
\text { significance }\end{array}$ \\
\hline Knowledge acquisition & 0.17 & 1.14 & 0.26 & \multirow{4}{*}{0.51} & \multirow{4}{*}{0.26} & \multirow{4}{*}{8.45} & \multirow{4}{*}{0.00} \\
\hline Generating knowledge & 0.45 & 3.65 & 0.00 & & & & \\
\hline Knowledge storing & 0.52 & 4.59 & 0.00 & & & & \\
\hline $\begin{array}{l}\text { Knowledge } \\
\text { implementation }\end{array}$ & 0.09 & 0.84 & 0.40 & & & & \\
\hline
\end{tabular}

Excellence: With low effect (22\%), only knowledge storing and implementation affected the excellence. This limited effect resulted of the lack of KM plans in the universities.

Table 8. Multivariate regression analysis for the KM components on excellence

\begin{tabular}{|c|c|c|c|c|c|c|c|}
\hline The dimension & B & $\mathbf{T}$ & $\begin{array}{c}\text { Statistical } \\
\text { significance }\end{array}$ & $\mathbf{R}$ & $\mathbf{R}^{2}$ & $\mathbf{F}$ & $\begin{array}{c}\text { Statistical } \\
\text { significance }\end{array}$ \\
\hline knowledge acquisition & 0.01 & 0.08 & 0.94 & \multirow{4}{*}{0.47} & \multirow{4}{*}{0.22} & \multirow{4}{*}{6.68} & \multirow{4}{*}{0.00} \\
\hline Generating knowledge & 0.05 & 0.42 & 0.68 & & & & \\
\hline Knowledge storing & 0.38 & 3.22 & 0.00 & & & & \\
\hline $\begin{array}{l}\text { Knowledge } \\
\text { implementation }\end{array}$ & 0.23 & 2.14 & 0.04 & & & & \\
\hline
\end{tabular}

Quality of E-learning: The restricted effect of KM on quality of EL was resulted of knowledge storing and implementation, but the acquisition and generating of knowledge did not affect the quality. This due to the lack of KM strategies in these universities that enable efficient application EL tools.

Table 9. Multivariate regression analysis for the KM components on quality of EL

\begin{tabular}{|c|c|c|c|c|c|c|c|}
\hline The dimension & B & $\mathbf{T}$ & $\begin{array}{c}\text { Statistical } \\
\text { significance }\end{array}$ & $\mathbf{R}$ & $\mathbf{R}^{2}$ & $\mathbf{F}$ & $\begin{array}{c}\text { Statistical } \\
\text { significance }\end{array}$ \\
\hline knowledge acquisition & 0.05 & 0.37 & 0.71 & \multirow{4}{*}{0.59} & \multirow{4}{*}{0.35} & \multirow{4}{*}{12.94} & \multirow{4}{*}{0.00} \\
\hline Generating knowledge & 0.09 & 0.74 & 0.46 & & & & \\
\hline Knowledge storing & 0.30 & 2.79 & 0.01 & & & & \\
\hline $\begin{array}{l}\text { Knowledge } \\
\text { implementation }\end{array}$ & 0.42 & 4.33 & 0.00 & & & & \\
\hline
\end{tabular}




\section{Discussion}

The objective of this research is to investigate the effect of KM on EL effectiveness. This effectiveness was investigate according to academic staff at private universities. The sample included both master degree and Ph. Degree academic staff in private universities. The sample included different academic ranks of the academic staff included. The experience of the academic staff helps the evaluation of the effect of KM on EL effectiveness.

There was a shortage on KM components in private universities. This indicates that the private universities do not have clear KM strategies and plans. The highest scoring was given for the storing and implementation of KM, but the shortages were in knowledge generation and acquisition which are considered basic components for the first two elements (storing and implementation) [17]. The shortages reported are expected to affect the organization of KM process with the educational institution [16].

On the other hand, the evaluation of achieving the goals of EL, its excellence, and quality of education got high scores. This can be explained through the ability of EL to introduced scattered objectives to transfer scatter knowledge to students. This evaluation was considered by each academic staff separately as each of them has his own perceptions of transferring knowledge. This fact was reported by [16] that EL is a tool to transmit knowledge but it is not necessary connected to KM of institution. They reported that strong connection of KM to EL will organize the process of transmitting KM through EL process. The effect of KM storing and implementation on EL efficiency was significant which approves the fact that EL efficiency can be achieved with scattered KM tasks. On the other hand, the efficiency can be achieved, if it was connected to clear KM plan.

Electronic leaning tools are used to improve the educational process $[13,15]$. To improve the education process and EL process, clear plans should be planned before connecting both KM and EL to maximize the benefits. Also, [14] reported that the lack of KM forms a shortage that affect the EL process in university enterprises.

\section{Conclusion and Recommendations}

The objective of this research is to investigate the effect of KM in universities on EL effectiveness. The results showed that the private universities lack a clear KM strategy and plans. This lead to the lack of control for the application of KM cycle, which facilitates the utilizing of EL in these universities. On the other hand, the utilization of EL effectiveness is scattered and cannot be controlled under the lack of integrated KM strategy. The results showed that effective EL is highly connected to clear KM plans.

The results of this research suggest that the private universities should build its KM model and testing it. The universities should start use this model and utilizing it in to achieve the goals of the university. On the other hand, the university should have model that connect the KM strategies and plans to increase the effectiveness of EL at 
universities. The KM strategies and plans should be connected with the objectives of EL. The universities should connect the goals of the strategy with the type of EL tools used to assure its' completely application.

\section{Future Work}

According to the results of this research, it recommended to investigate the type of effectiveness EL tool according to the objective of the use of these tools through connecting these tools with KM strategy in educational institutions. More research can be through building a KM model for academic institution and EL tools to apply this model and apply it on a sample of academics and students to measure its effectiveness.

\section{$8 \quad$ References}

[1] Agarwal, N.; Marouf, L. Initiating knowledge management in colleges and universities: A template. International Journal of Knowledge Content and Technology, Vol. 4(2), 2014, 67-95. https://doi.org/10.5865/ijkct.2014.4.2.067

[2] Ahmadi, A.A., \& Ahmadi, F. Knowledge management in Iranian university (Case Study Shushtar University). Interdisciplinary Journal of Contemporary Research in Business, Vol. 4(5), (2012), pp.653-667.

[3] Girard, J. \& Girard, J. Defining knowledge management: Toward an applied compendium. Online Journal of Applied Knowledge Management. Vol. 3(1), (2015).

[4] Igbinovia, Magnus \& Ikenwe, Iguehi. Knowledge management: processes and systems. Information Impact: Journal of Information and Knowledge Management. 8. 26. 10.4314/iijikm.v8i3.3, 2018. https://doi.org/10.4314/iijikm.v8i3.3

[5] Islam, S.; Kunifuji, S.; Miura, M.; Hayama, T. Adopting knowledge management in an Elearning system: Insights and views of KM and EL research scholars. Knowledge Management \& E-Learning: An International Journal, Vol. 3(3), 2011, pp. 375-398. https ://doi.org/10.34105/j.kmel.2011.03.027

[6] Kalogiannakis, M., \& Papadakis, S. Evaluating pre-service kindergarten teachers' intention to adopt and use tablets into teaching practice for natural sciences. International Journal of Mobile Learning and Organisation, 13(1), 2019, 113-127.

[7] Kalogiannakis, M., \& Papadakis, St. The dual form of further education of educators in ICT: technological and pedagogical training. In C. Constantinou, Z. Zacharias \& M. Papaevripidou (Eds.) Proceedings of the 8th International Conference On Computer Based Learning in Science, Heraklion, 30 June - 6 July 2007, 265-276.

[8] Khan, B. H. A framework for web based learning. Engelwood Cliffs, NJ: Educational Technology publication, 2001.

[9] Kikilias, P., Papachristos, D., Alafodimos, N., Kalogiannakis, M. \& Papadakis, St. An Educational Model for Asynchronous E-Learning. A case study in a Higher Technology Education, In D. Guralnick (ed.) Proceedings of the International Conference on E-Learning in the Workplace (ICELW-09), 10-12 June 2009, New York: Kaleidoscope Learning (CD-Rom), 2009. 
[10] Masic, B.; Nesic, S.; Nikolic, D.; Dzeletovic, M. Evolution of knowledge management. Industrija. Vol. 45(2), 2017, pp.127-147. https://doi.org/10.5937/industrija45-13201

[11] Matos, J.; Pedro, A.; Piedade, J. Integrating digital technology in the school curriculum. iJET, Vol. 14(21), 2019.

[12] O'dell, C., \& Hubert, C. The new edge in knowledge: How Knowledge Management is changing the way we do business. Hoboken, NJ: Wiley, 2011. https://doi.org/10.1002/ 9781119200802

[13] Otair, M.; Al-Jedaiah, M.; Al-Zoubi, A.; Al-Refaee, A. Sharing of learning material on mobile devices through Bluetooth technology. iJET. Vol. 5(1), 2010, pp. 16-21. https://doi. org/10.3991/ijet.v5i1.1170

[14] Papadakis, St., \& Kalogiannakis, M. Mobile educational applications for children. What educators and parents need to know. International Journal of Mobile Learning and Organisation (Special Issue onMobile Learning Applications and Strategies), Vol. 11(3), 2017, pp. 256-277.

[15] Papadakis, St., Kalogiannakis, M., Sifaki, E., \& Vidakis, N. Evaluating Moodle use via Smart Mobile Phones. A case study in a Greek University, EAI (European Alliance for Innovation) Endorsed Transactions on Creative Technologies, 5(16), 2018 e1, 1-12, http://eudl.eu/pdf/10.4108/eai.10-4-2018.156382 https://doi.org/10.4108/eai.10-4-2018.15 $\underline{6382}$

[16] Pattnayak, Jui; Pattnaik, S.; Dash, P. Knowledge Management in E-Learning A Critical Analysis. International Journal of Engineering and Computer Science. 10.18535/ijecs/v6i5.56, 2017.

[17] Rahimi, E.; Rostami, N.; Shad, F.; Vafaei, V. The importance of knowledge management on innovation. Vol. 5(1), 2017, 68-73.

[18] Raudeliūnienè, J.; Vida Davidavičienè, Artūras Jakubavičius. Knowledge management process model. Entrepreneurship and Sustainability Issues, Entrepreneurship and Sustainability Center, 2018, 5 (3), pp.542 - 554. ff10.9770/jesi..3(10)ff. ffhal-01773979f, 2018. https://doi.org/10.9770/jesi.2018.5.3(10)

[19] Salleh, Kalsom. (2010). E-Learning, Knowledge Management and Learning Organization: An Integrative Perspective, 2010.

[20] Sammour, G.; Schreurs, J.; Al-Zoubi, A.; Vanhoof, K. The role of knowledge management and e-leaning in professional development. Int. J. Knowledge and Learning, Vol. 4(5), 2008, pp.465-477. https://doi.org/10.1504/ijkl.2008.022064

[21] Schliercher, A. The Future of Education and Skills: Education 2030. OECD.

[22] Shamizanjani, M.; Naeini, S.; Nouri, M. (2013). Knowledge management mechanisms in e-learning environment: A conceptual model. Knowledge management \& E-Learning, vol. 5(4), 2018, pp. 468-491. https://doi.org/10.34105/j.kmel.2013.05.034

\section{$9 \quad$ Author}

Mohamad Noor Al-Jedaiah is an Associate Professor in the department of Business Administration at Jadara University.

Article submitted 2019-09-11. Resubmitted 2019-11-25. Final acceptance 2019-11-25. Final version published as submitted by the authors. 